NBER WORKING PAPER SERIES

\title{
HYPERINFLATION WITH CURRENCY SUBSTITUTION: INTRODUCING AN INDEXED CURRENCY
}

Federico Sturzenegger

Working Paper No. 4184

\section{NATIONAL BUREAU OF ECONOMIC RESEARCH 1050 Massachusetts Avenue \\ Cambridge, MA 02138 \\ October 1992}

Department of Economics, University of California, Los Angeles and National Bureau of Economic Research. Mailing Address: 405 Hilgard Ave., Los Angeles, CA 90024-1477. sturzene@sscnet.econ.ucla.edu. I would like to thank Rudiger Dornbusch, Andy Neumeyer, Peter Temin, Holger Wolf and two anonymous referees for useful suggestions. The usual caveat applies. This paper is part of NBER's research programs in International Finance and Macroeconomics and Monetary Economics. Any opinions expressed are those of the author and not those of the National Bureau of Economic Research. 
NBER Working Paper \#4184

October 1992

\title{
Hyperinflation with Currency Substitution: Introducing an \\ Indexed Currency
}

\begin{abstract}
Currency substitution (CS) and financial adaptation are in general believed to increase the equilibrium rate of inflation. This result derives from a setup in which the government finances a certain amount of real resources through money printing and where CS reduces the base of the inflation tax. This paper shows this intuition wrong for those situations where the hyperinflation is expectations-driven. Incorporating CS in an Obstfeld-Rogoff (1983) framework I show reduces the inflation rates along the hyperinflationary equilibrium. The intuition is simple: if agents have an easy way of substituting away from domestic currency then the required inflation rates to sustain a path where real balances disappears is necessarily lower. The implications of the model are then tested empirically.
\end{abstract}

Federico Sturzenegger

Department of Economics University of California, Los Angeles

405 Hilgard Avenue

Los Angeles, CA 90024-1477

and NBER 


\section{Introduction}

Several countries have experienced monetary systems in which two currencies issued by the same government serve as legal tender at the same time. The best known cases are those of the Soviet Union between November 1922 and March 1924 and Hungary immediately after World War II. In the Soviet Union, depreciating Soviet rubles circulated side by side with the stable chervonets. In IIungary, the tax pengö, an indexed currency, was used as a means of payment together with the regular pengö. But the experience with indexed currencies belongs not only to history. Beginning in August 1990, the new córdoba is circulating together with the gold córdoba in Nicaragua and starting in January 1992, Ukranian coupons go side by side with Soviet rubles."

During the 1980s, Latin America has experienced an increase in the phenomenon of dollarization by which US dollars become used for transactions purposes. The process of dollarization is similar to that of introducing an indexed currency, as it also provides an alternative means of transacting. The main difference between the establishment of indexed currencies and dollarization lies in the financing of the monetary stock. The process of dollarization entails the need to run current account surpluses in order to "purchase" the stock of monetary balances.

Usually, in the dual currencies experiences, one of the two currencies maintained stable parity, while the other depreciated very quickly. The conventional wisdom is that it is the introduction of a stable currency that it accelerates the rate of depreciation of the original one. ${ }^{2}$ The argument is that introducing a second currency decreases the demand for the old

\footnotetext{
${ }^{1}$ Other examples are the issue of provincial currency in Argentina in the 1980s and the issues of private money during the German hyperinflation, which seems to have amounted to about six times the official money supply. See Keller (1958).

${ }^{2}$ To see this approach applied to the Hungarian experience, see Bomberger and Makinen (1980) and
} 
money. The excess supply of currency increases the inflation rate as people try to reduce their holdings of currency.

This paper tries to challenge this interpretation on both theoretical and empirical grounds. First, I develop a theoretical model in which the inflation rate is a bubble on the price level. My basic framework follows previous work by Sidrauski (1967) on models of money in the utility function and Obstfeld and Rogoff (1983) for its extension to hyperinflations. I show that if an alternative monetary asset is introduced, the rate at which inflation accelerates declines. Although initially, the rate of inflation may increase or decrease, depending upon how strong a decline in monetary balances is induced by the currency substitution process, the rate of inflation under currency substitution will eventually be smaller than that without currency substitution along the hyperinflation path.

I then test the prediction of the model for two historical episodes. First, I consider the case of the introduction of indexed currency in the Soviet Union in the 1920s. Second, I discuss the case of dollarization in the Argentine hyperinflations of 1989 and 1990 . Both experiences are shown to be consistent with my model.

The paper is organized as follows. Section 2 describes the basic Obstfeld-Rogoff framework. Section 3 derives the appropriate propesties of a utility function that includes two monies in its argument. Section 4 presents a model with two fiat currencies. Section 5 discusses the empirical testing of the model. Finally, Section 6 contains some policy and welfare implications.

(1983), Kaldor (1946a) and (1946b), and Nogaro (1948). 


\section{The Basic Framework}

Consider the Sidrauski (1967) model with no capital; the problem is:

$$
\operatorname{Max} V=\int_{0}^{\infty} u\left(c_{t}, m_{t}\right) e^{-\delta t} d t
$$

subject to

$$
c_{t}+\frac{d m_{t}}{d t}=y-\pi_{t} m_{t}+x_{t}
$$

where $c_{t}$ is the agent's consumption in period $t, m_{t}$ is his holding of real monetary balances, $y$ is the agent's fixed endowment, $\pi_{t}$ is the inflation rate, and $x_{t}$ is government transfers. The first-order conditions for this problem are

$$
\begin{gathered}
u_{c}(c, m)=\lambda, \\
\frac{d \lambda / d t}{\lambda}=\delta+\pi-u_{m}(c, m) / \lambda, \\
\lim _{t \rightarrow \infty} \lambda e^{-\delta t} m_{t}=0,
\end{gathered}
$$

where I have dropped the time subscripts for convenience. Furthermore, we have that

$$
\dot{m} / m=\sigma-\pi
$$

and

$$
x=\sigma m,
$$


where $\sigma$ is the rate of growth of the nominal stock of money.

Substitute equations (6) and (7) into (2) to obtain the equilibrium level of consumption, $c_{t}=y$. If I assume that the utility function is separable in consumption and real money balances, the fact that $c_{t}=y$ (where $y$ is constant) implies that the marginal utility of consumption must be constant, or that $\dot{\lambda}=0$. I can therefore normalize $c$ such that $\lambda=u_{c}=1$. Equation (4) then becomes

$$
u_{m}(m)=\delta+\pi
$$

So, substituting (6) into (8) gives

$$
\dot{m}=(\delta+\sigma) m-u_{m}(m) m
$$

Equation (9) is a differential equation in $m$. By taking the derivative with respect to $m$ near the steady state $\left(-u_{m m} m>0\right)$, I immediately get that the equation is unstable. This ties down the price level by determining a unique steady state level of real money balances. But the steady state is not the unique equilibrium. Obstfeld and Rogoff (1983) have shown that in this model, while hyperdeflations can be ruled out (because they violate the transversality condition), the same is not true of hyperinflations. As long as

$$
\lim _{m \rightarrow 0} m u_{m}(m)=0
$$

a rational hyperinflation may take place even with constant money growth.

Figure 1 shows the dynamics of equation (9). The full line corresponds to the case in which condition (10) is satisfied. $A$ is the steady state. At $A, u_{m}=\delta+\sigma=\delta+\pi$, which is the traditional money demand obtained in these models. The hyperdeflationary 
solutions are located to the right of the steady state and generate an unbounded growth of real monetary balances.

The solutions to the left of the steady state generate a fall in real money and therefore correspond to hyperinflationary paths. Given that for these paths, $\dot{m}=0$ when $m=0$, the origin is an alternative steady state and corresponds to a nonmonetary equilibrium.

Figure 1: Monetary Dynamics in the Obstfeld-Rogoff Model

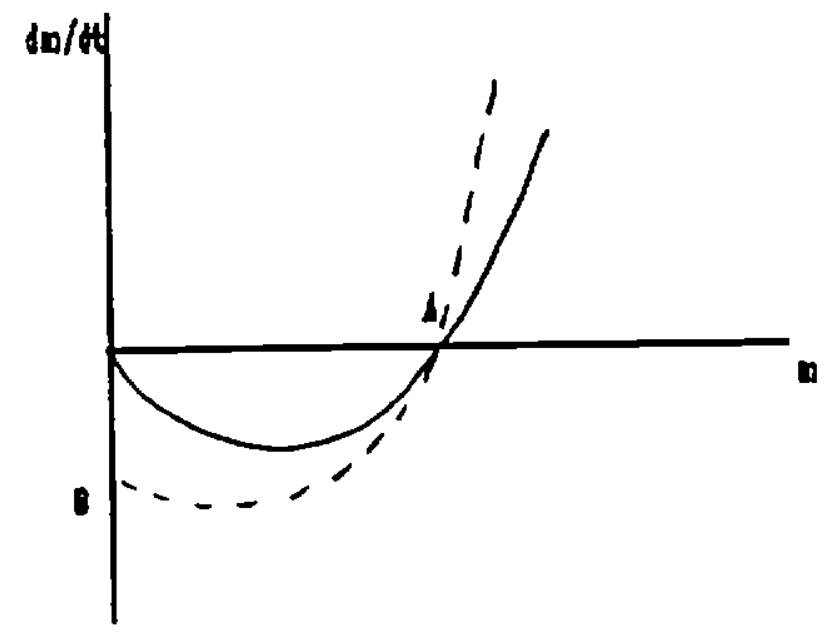

Alternatively, we may have that

$$
\lim _{m \rightarrow 0} m u_{m}(m)>0
$$

This case is represented by the dashed line in Figure 1. $A$ is still a steady state, and the hyperinfiationary paths are still to the left of $A$. On the hyperinflationary solution path the economy eventually reaches point $B$, at which point money holdings become negative $(\dot{m}<0)$. These paths are infeasible, and therefore must be ruled out. 
It is interesting to note that the assumption that eliminates hyperinflations implies that money has to be essential, in the sense that its marginal utility must increase faster than the rate at which money balances converge to zero. In particular $u_{m} \rightarrow \infty$ is a necessary condition to rule out hyperinflations. This condition is likely to be false when alternative currencies are available, making it more difficult to rule out hyperinflations in those settings.

\section{The Properties of the Utility Function}

To extend the previous set up to one in whiclı currency substitution occurs, it is important to characterize the proper utility function to be used. This is particularly important because we know from previous literature that the results depend critically on the assumptions on the cross-partial derivatives between the two monetary assets. Liviatan (1981) showed that using traditional utility functions with positive cross partials, i.e. in which $u_{m_{1} m_{2}}>0$, generated results that were counter intuitive. ${ }^{3}$

While the consensus in the literature is that the appropriate utility function should be characterized by negative cross partials (i.e., $u_{m_{1} m_{2}}<0$ ), to date no utility function that exhibits these properties has been constructed. In this paper, I proceed to derive such a utility function explicitly from a Baumol-Tobin-Barro transactions model.

The traditional Baumol-Tobin-Barro setup starts by postulating a model in which individuals require monetary holdings to purchase a constant flow of consumption, $c$. If agents run short of domestic currency then they must incur a cost in order to obtain additional currency. These costs are usually associated with the costs of going to the bank or the costs associated with converting illiquid assets into currency. Holding domestic currency entails

\footnotetext{
${ }^{3}$ Possible solutions were suggested by Calvo (1985) and Engel (1989).
} 
a loss in terms of forcgone interest. To reduce the amount of money held, the individual can increase the number of conversions from indexed assets to currency. In addition, this model allows the individual to have the option to commit a certain amount of his assets to be held as foreign or indexed currency. This renders the interest rate and the liquidity at the same time but entails a cost associated with transacting through this more sophisticated transactions mechanism.

For simplicity I will assume that the agent commits to use a certain amount of indexed currency $\left(m_{2}\right)$ each time he obtains domestic currency $\left(m_{1}\right)$ and that the costs associated with using this indexed currency are quadratic in $m_{2}$. The agent minimizes transactions costs, $L$, equal to

$$
L=\left(\frac{c-N m_{2}}{2 N}\right) i+N k_{1}+N k_{2} m_{2}^{2}
$$

where $N$ is the number of conversions or trips to the bank and $k_{1}$ and $k_{2}$ are constants that determine the real cost of both kind of transactions. $i$ is the nominal interest rate. Total liquidity costs are equal to the foregone interest on domestic currency holdings plus transactions costs that equal the cost of "going to the bank" plus the cost of operating through sophisticated financial instruments. Minimization of (12) with respect to $N$ and $m_{2}$ gives the demand functions for both currencies. Average domestic monetary holding will equal to

$$
m_{1}=\frac{c-N m_{2}}{2 N}
$$

equivalently, 


$$
N=\frac{c}{2 m_{1}+m_{2}}
$$

Feenstra (1986) showed that if we define $c$ " as "gross consumption" ie. as including "net consumption" (c) and transactions costs, then there is an equivalence between the problem (1)-(2) defined over $c^{*}$ and an analogous intertemporal maximization problem in which the agent maximizes a utility function that depends only on $c$ subject to a budget constraint containing a liquidity cost or transactions cost. My objective is to find the corresponding utility function that makes these two problems analogous in this extended set up.

From above, I get that

$$
c^{*}=c+k_{1} N+N k_{2} m_{2}^{2}
$$

Now, to have an appropriate money in the utility function, it must be that $V\left(c^{*}, m_{1}, m_{2}\right)=$ $u(c)$, where $u(c)$ is the original utility function of the liquidity cost problem. Substituting for $N$ from (14), I obtain

$$
V\left(c^{*}, m_{1}, m_{2}\right)=u\left(\frac{c^{*}}{1+\frac{k_{1}}{2 m_{1}+m_{2}}+\frac{k_{2} m_{2}^{2}}{2 m_{1}+m_{2}}}\right) .
$$

In particular, if $u(c)=\log (c)$, then the utility function takes the form

$$
V\left(c^{*}, m_{1}, m_{2}\right)=\log \left(c^{*}\right)-\log \left[1+\frac{k_{1}}{2 m_{1}+m_{2}}+\frac{k_{2} m_{2}^{2}}{2 m_{1}+m_{2}}\right],
$$

i.e., the utility function is separable in both consumption and liquidity services.

Now, consider the properties regarding the relation between both monetary assets given by equation (17). For $V$ to be well defined, we require that $V_{i}>0$ and that $V_{i i}<0$, where 
$i=\left\{c, m_{1}, m_{2}\right\}$. The two conditions are obviously satisfied for $c^{*}$ and $m_{1}$, as can be seen by simple differentiation of (17). For $m_{2}$, I obtain

$$
\frac{\partial V}{\partial m_{2}}=\frac{1}{2 m_{1}+m_{2}}-\frac{1+2 k_{2} m_{2}}{2 m_{1}+m_{2}+k_{1}+k_{2} m_{2}^{2}}>0
$$

which will only be positive if $k_{2}$ is small enough. Equation (18) states that the marginal benefit from holding indexed currency which is the savings of transactions costs, must exceed the marginal costs induced by using more of this currency. ${ }^{4}$

I now compute the cross-partial derivative which equals

$$
-\frac{\partial V}{\partial m_{1} \partial m_{2}}=\frac{1}{\left(2 m_{1}+m_{2}\right)^{2}}-\frac{1+2 k_{2} m_{2}}{\left(2 m_{1}+m_{2}+k_{1}+k_{2} m_{2}^{2}\right)^{2}}
$$

It is easy to show that if (18) is satisfied, the right hand side of (19) will also be positive. To see this result, multiply both denominators of (18) by $\left(2 m_{1}+m_{2}+k_{1}+k_{2} m_{2}^{2}\right)$. Notice that the resulting positive expression is smaller than that in (19), which therefore is positive as well. This proves that under the necessary conditions for (17) to be a well-defined utility function, the cross partials between currencies have to be negative.

In what follows, I work with a utility function that satisfies the properties shown for (17), i.e., separability in both consumption and liquidity services and negative cross partials for both monies.

\section{The Two Fiat Currency Model}

Let the representative agent model solve the problem (where again I drop time subscripts when no confusion arises)

\footnotetext{
${ }^{4}$ The second order derivatives are again negative for $c^{*}$ and $m_{1}$ and for $m_{2}$ for small enough $k_{2}$.
} 


$$
\operatorname{Max} V=\int_{0}^{\infty}\left[u(c)+l\left(m_{1}, m_{2}\right)\right] e^{-\delta t} d t
$$

subject to

$$
\dot{m}_{1}+\dot{m}_{2}+\pi m_{1}+\pi_{2} m_{2}+c=y+x_{1}+x_{2}
$$

where the utility function satisfies the properties outlined in Section 3.

The agent can accumulate both kinds of monies or consume. His income is a fixed endowment, $y$, plus government transfers in both monies. The first-order conditions for this problem are

$$
\begin{gathered}
u_{c}=\lambda, \\
u_{m_{1}}-\lambda \pi_{1}-\mu=0, \\
u_{m_{2}}-\lambda \pi_{2}-\mu=0, \\
-\dot{\lambda}+\delta \lambda=\mu,
\end{gathered}
$$

and

$$
\left(m_{1}+m_{2}\right) \lambda e^{-\delta t}=0 .
$$

Also, I get that

$$
\dot{m_{1}} / m_{1}=\sigma_{1}-\pi_{1}
$$


and

$$
m_{2} / m_{2}=\sigma_{2}-\pi_{2}
$$

Substituting (27) and (28) into the budget constraint (and using conditions analogous to (7) for government transfers in each currency) gives $y=c$ as before. I again normalize in such a way that $\lambda=1$. Substituting (23) and (24) into (27) and (28) gives two differential equations in both real money balances:

$$
\dot{m_{1}}=\left(\sigma_{1}+\delta-u_{m_{1}}\right) m_{1}
$$

and

$$
\dot{m}_{2}=\left(\sigma_{2}+\delta-u_{m_{2}}\right) m_{2}
$$

Equations (29) and (30) describe the evolution of a dynamic system in two variables. ${ }^{5}$ Notice that in the steady state, $\sigma_{1}=\pi_{1}$ and $\sigma_{2}=\pi_{2}$ and that therefore the relative money holdings will be a function of the relative nominal interest rates quoted in each currency. Linearizing this system around the steady state generates a dynamic system with two positive eigenvalues. ${ }^{6}$

This system is completely unstable with the unique convergent path being the steady state. In addition if the condition analogous to (10) is satisfied, the economy presents a

\footnotetext{
SThe slopes of $\dot{m}_{1}=0$ and $\dot{m}_{2}=0$ are given by $-u_{m_{1} m_{2}} / u_{m_{1} m_{1}}$ and $-u_{m_{3} m_{j}} / u_{m_{1}} m_{j}$. The concavity of $u$ allows me to determine that the equation for $\dot{m}_{2}=0$ has a higher slope in absolute value.

The trace equals $-\left(m_{1} u_{m_{1} m_{1}}+m_{2} u_{m_{2} m_{j}}\right)>0$ indicating the presence of at least one positive root. Furthermore the determinant has the sign of $u_{m_{1} m_{1}} u_{m_{2} m_{2}}-u_{m_{1} m_{j}}^{2}$ which by concavity is assumed to be positive. This indicates that both roots have the same sign, i.e. positive.
} 
multiplicity of equilibria, described by the hyperinflation paths converging on the single currency equilibria.

Figure 2: Monetary Dynamics in the Two Fiat Currency Model

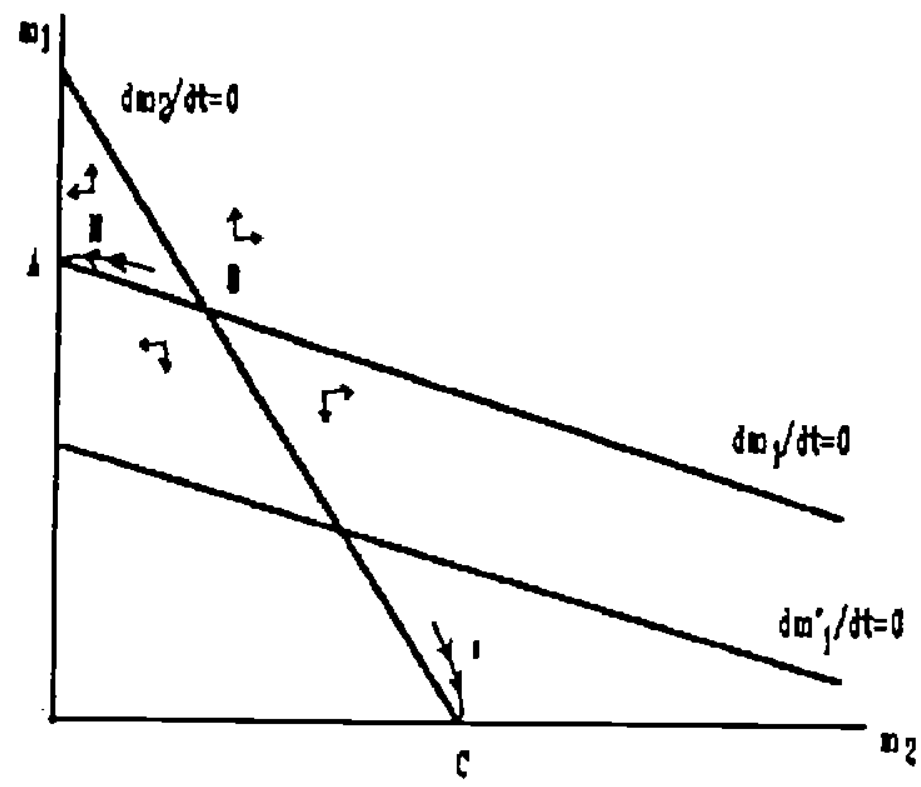

The phase diagram for the linearized system is given in Figure 2. Points $A$ and $C$ represent the one-currency equilibria. Along the branch denoted $I, m_{1}$ suffers a hyperinflation. Along II, it is $m_{2}$ that asymptotically disappear's. As both variables are jump-variables, the economy can move to any point along this path (II) and still satisfy the dynamic equations that describe the evolution of the monetary equilibrium.

It is interesting to do comparative statics on this model under the assumption that we begin at the steady state without hyperinflation (point $A$ ). Suppose I introduce a new currency, say $m_{2}$. This moves the equilibrium from point $A$ to point $B$. Because the cross marginal utilities are negative, the introduction of $m_{2}$ induces a decrease in the equilibrium holdings of $m_{1}$. This is achieved by a jump in the price level of the original currency. 
Suppose now I increase the rate of noney growth for $m_{1}$. This shifts the $\dot{m}_{1}=0$ locus downwards to $\dot{m}_{\mathfrak{l}}^{\prime}=0$. The final equilibrium entails lower real holdings of $m_{1}$ and greater holdings of $m_{2}$, i.e., a price level jump in terms of the "worsened" currency and a fall of the price level measured in terms of the "new" or more stable one. The relative price level shift implies lower real holdings of the original money in steady state. Therefore, the steady state implications of the model are the expected ones and to some extent work as a Gresham's Law in reverse: across steady states, good money displaces bad.

Now return to the initial steady state (point $A$ ). Assume now that while one currency is evolving through a hyperinflationary path, another currency "backed" by the government is introduced..$^{7}$ Furthermore, suppose it is $m_{2}$ that is backed. I now examine how the introduction of this second currency affects the dynamic process for the initial one. $m_{1}$ (using the transversality condition) will evolve according to

$$
m_{1}(t)=e^{\left(\sigma+\delta-u_{m_{1}}\left(m_{1} m_{2}\right)\right) t} .
$$

For the hyperinflationary paths we are considering, the coefficient of the exponent is negative; as we are to the left of the steady state ( $A$ in Figure 1 ), real money holdings approach zero.

The rate of the depreciation of real money balances is given by the exponent $\sigma+\delta-$ $u_{m_{1}}\left(m_{1}, m_{2}\right)$. So, the effect on the rate of decline of monetary balances will be given by the net effect on the marginal utility of money. There are two effects at work. On the one hand the increase in holdings of $m_{2}$ will push the marginal utility downward. On the other hand, the fall in the holdings of $m_{\mathrm{I}}$ will have the opposite effect. I discuss the net effect with the help of Figure 3.

\footnotetext{
"In this context, "backing" means forcing condition (11) to hold in the monetary equilibrium.
} 
Figure 3 integrates Figures 1 and 2 . The outer equation for $\dot{m}_{1}\left(\dot{m}_{1}\left(m_{2}=0\right)=0\right.$ ) is constructed for the case in which $m_{2}=0$ and corresponds to that in Figure 1. Now, consider a point along the hyperinflationary path for currency $m_{1}$ say, point $C$. The inner curve for $\dot{m}_{1}$ is constructed for the corresponding value of $m_{2}$. To know if the inflation rate of the original currency increases or decreases, we have to see if $\dot{m} / m$ increases or decreases upon moving to the new equilibrium point. Along a hyperinflationary solution the initial money balances for $m_{1}$ are bounded below by $\underline{m_{1}}$, the amount of real money balances corresponding to the new equilibrium, and above by $\bar{m}_{1}$, the maximum possible holding of money balances before the introduction of the alternative currency. It can now be seen from Figure 3 that if the initial monetary balances were above $m^{*}$, then $\dot{m} / m$ (the slope of the line which starting at the origin goes through a particular point in the $\dot{m}_{1}=0$ curve) increases in absolute value in the transition; therefore from (27) the inflation rate increases as well. Conversely, if initial money balances are below $m^{*}$, the rate of inflation falls.

Irregardless of the initial effect on the level of the inflation rate, if the new currency is a substitute for original currency in the sense of Section 3, then the rates of inflation required to sustain the hyperinflation path will be lower than before. Equation (29) implies that the rate of inflation depends on the value of the marginal utility of money, $u_{m}$. For the same holdings of domestic currency, currency substitution lowers the marginal utility of money thereby reducing the rate of inflation. In addition, the rate of growth of inflation falls as along the hyperinflation path (I) described in Figure 2, the holdings of the indexed currency increase. This reduces the marginal utility of money as compared with an equivalent change in monetary holdings without the possibility of substituting away from domestic currency.

A fall in the rate of increase of the inflation rate due to the introduction of a more 
Figure 3: Effects of a Second Currency on Monetary Dynamics

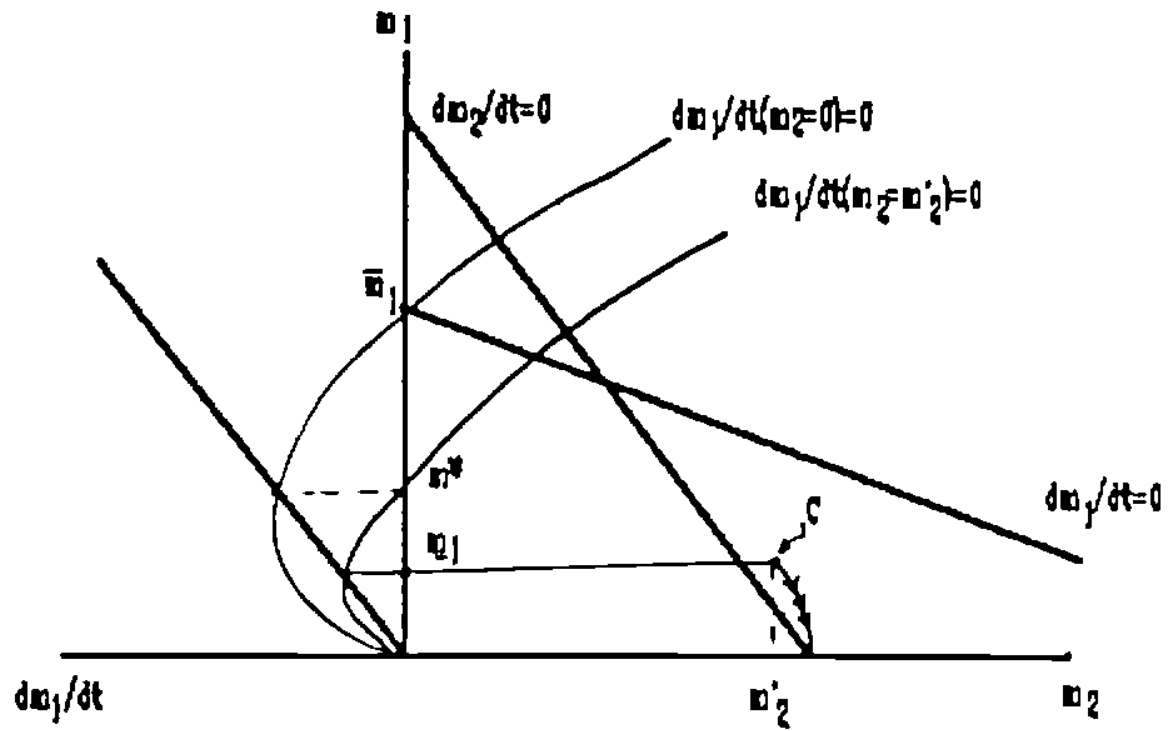

"stable" currency and a reduction in the inflation rates achieved during the hyperinflation goes against the conventional wisdom. But, the intuition for this seemingly puzzling result is rather straightforward. Along the hyperinflationary path (I), people are willing to reduce monetary balances because they expect the inflation rate to increase in the future. If money is "essential" in the sense that its marginal utility is very high, then the inflation rate required to induce people to substitute out of this currency must be very large. If money losses this "essentiality" property -because a very close substitute develops or becomes available- then the inflation rate required to sustain a path with declining real monetary balances falls. 


\section{Empirical Testing}

The hypothesis that hyperinflation is a bubble on the price level has been empirically tested by Flood and Garber (1980), Flood, Garber, and Scott (1984), and Casella (1989). The last two papers were unable to reject the existence of a bubble on the price level.

In this paper I follow Flood and Garber (1980) and test for bubbles for two historical episodes. First, I consider the introduction of the chervonets, an indexed currency, in November 1922 in the Soviet Union. I then consider the two Argentine hyperinflations of May-August 1989 and of December-March 1990. The Argentine experiences present a ideal case studies because an intense process of financial adaptation took place in the short time span between the two hyperinflations.

The model discussed in this paper generates two predictions. The first is that both monies are substitutes and that therefore the demand for the original currency falls upon introduction of the indexed alternative. The second is that bubbles are important in the hyperinflationary process and that the value of the bubble grows at a smaller rate and eventually is smaller with currency indexation than without. The first prediction of the model derives from the negative cross-partial derivative derived in Section 3 . I tested this by testing whether that money demand falls when the new currency is introduced or financial adaptation takes place. The second hypothesis was tested by estimating the value of the bubble before and after the monetary reform and testing whether the bubble grows at a slower rate with currency substitution than without.

To estimate the value of the bubble, I used a variation of the empirical model developed by Flood and Garber (1980). Their model is a discrete time, partial equilibrium version of the theoretical model considered in this paper. Their model also allows for changes in the 
rate of monetary growth; since the rate of money growth is not constant in the real world, it must be accounted for in the econometric testing,

Specifically, the model consists of a Cagan money demand function of the form

$$
m_{t}-p_{t}=\gamma+\alpha E_{t-1}\left(\pi_{t}\right)+\epsilon_{t}
$$

where $m_{l}$ and $p_{t}$ are the logs of nominal money balances and the price level. As usual, $E_{t-1}$ denotes the expectation conditional on the information available at the beginning of the period. Finally, $\epsilon_{t}$ is a random shock. The money demand semielasticity, $\alpha$, is negative. The rational expectations solution of (32) for the inflation rate is

$$
E_{t-1}\left(\pi_{t}\right)=A_{0} \phi^{l}-\frac{\phi^{-1}}{\alpha} \sum_{i=0}^{\infty} E_{t-1}\left(\sigma_{t+i}\right) \phi^{-i},
$$

where $\phi=\frac{\alpha-1}{a}>1$ and $A_{0}$ is an arbitrary constant. The term $A_{0} \phi^{t}$ corresponds to the bubble and describes the solution considered in this paper. The second term in (33) represents the fundamentals driving the rate of inflation. My model predicts that with currency substitution, $\phi$ should be smaller and the bubble will grow at a lower rate. A fall in $\phi$ takes place upon an increase in the absolute value of $\alpha$. Both predictions of the model are therefore tied to the behavior of $\alpha$.

The empirical implementation of the model involved the following steps. First, I tested for the integratedness of my variables: the rate of inflation and the real stock of money. I then computed a money demand function that allows for a change in monetary holdings at the moment of the introduction of currency indexation. This consisted of testing for an appropriate cointegrating vector between real money demand and inflation. If my money demand function cointegrates, then I know that the estimators are superconsistent, ie., 
converge to the true population moments at a rate faster than the usual $T^{\frac{1}{2}}$. Unfortunately, the limiting distribution is nonstandard and skewed to the left. (See Stock (1987).) In order to obtain consistent estimators of the standard errors, I ran a Stock and Watson (SW) regression. (See Stock and Watson, (1989).) The SW procedure entails running GLS on the cointegrating equation and adding the backward and forward lags of all the residuals of any cointegrating relationship present between the regressors. Alternatively, OLS with Newey-West corrected standard errors (see Newey and West (1987)) also attain consistency. As the inflation rate is an $I(1)$ process in my specification, the cointegrating vectors that had to be added to the system are the differences in the inflation rate. In general, three forward and three backward lags were used.

Once a consistent estimate of the semielasticity of money was obtained, I computed $\phi$ and estimated, again using the SW procedure, the inflation prediction equation (33). This enables me to test the significance of the bubble term and to estimate the value of $A_{0}$. Finally, I could compute, given the value of $\phi$ and $A_{0}$, the corresponding bubble for each hyperinflation.

Estimation of (32) was done by substituting the actual inflation rate for the expected value. This would in general introduce an errors in variables problem. In this case, due to the integratedness of the equation, the error term is asymptotically irrelevant. (See Engle and Granger (1987)). Therefore, if real money and inflation are in fact cointegrated, my estimators of the coefficients in equation (32) are consistent. 


\subsection{The Soviet Hyperinflation}

The history of Soviet inflation begins with the restriction of convertibility shortly after the beginning of World War I. ${ }^{8}$ During the years until 1921, an important fraction of government spending was financed by money issue, even though shortly after the revolution, regulations issued by the People's Commissariat of Finance restricted the circulation of currency in an attempt to construct a money-free economy. As the economy reverted to barter, economic activity collapsed, and real money holdings declined sharply. After 1921, a strong turn in economic policies took place under the "New Economic Policy" program. The NEP accomplished a wide liberalization of the monetary and financial markets. Inflation nevertheless continued unabated. The Soviet government increasingly became convinced of the need of establishing a stable currency. Finally, the issue of the chervonets was agreed upon. The state bank was responsible for the issue, but it was required to secure up to no less than one quarter of the sum issued by precious metals and stable foreign currency. Even though it was not a convertible currency, the value of the chervonets remained stable during 1923, while the Soviet ruble continued to depreciate at an ever increasing rate.

Initially, chervonets were regarded with distrust but afterwards quickly began to substitute for old Soviet rubles. Finally, in March 1924 the old Soviet ruble was liquidated by being exchanged at fixed parity with the cliervonets. When the Soviet rubles were withdrawn from circulation, (on March 10,1924), each new ruble was exchanged for 50,000,000 prerevolutionary rubles.

I first tested for the integratedness of the money demand variables: the stock of real monetary balances and the inflation rate. The $A D F_{6}{ }^{9}$ statistics for real monetary balances

\footnotetext{
'Data was obtained from Cagan(1956), Katzenellenbaum (1925) and Yurovsky (1925).

'The subscript in the $A D F$ coefficient indicates the number of lags used in the computation of the
} 
and inflation equal -1.16 and -0.27 , respectively, which when compared with the critical value of -2.89 , does not allow me to reject the hypothesis of integratedness. ${ }^{10}$

I next computed the SW money demand function for the period between August 1919 and April 1924. The estimated equation is

$$
\begin{aligned}
m_{t}= & 18.44+2.38 D_{t}-1.79 \pi_{t}-2.26\left(\pi_{t} D_{t}\right)+0.35 t-4.44 t^{\frac{1}{2}}-.21 C h e \tau_{t} \\
& (13.45)(9.19)(-4.54)(-5.60) \quad(9.49)(-9.51) \quad(-7.67)
\end{aligned}
$$

where $m_{t}$ is real holdings of Soviet rubles, $\pi_{t}$ is the inflation rate, and $t$ is a time trend. The dummy $D_{t}$ takes a value of one for periods after January 1923. While chervonets were officially introduced in late November 1922, they only started to circulate in significant quantities in January 1923. Both time trends capture the progressive process of financial adaptation that takes place in high inflation situations. The variable $\mathrm{Cher}_{t}$ measures the real stock of chervontsi in circulation. The money demand function implied by equation (29) together with the assumption on the cross-partial derivatives derived in Section 3 suggests that this variable should enter with a negative coefficient. Newey-West corrected standard errors were used to compute the t-statistics reported. ${ }^{11}$

A standard $A D F_{3}$ test gave a statistic of -2.94 , rejecting the hypothesis of nonstationarity at the 5 percent level. I conclude then that (34) is a cointegrating vector and therefore that the estimated parameters are consistent to their true population counterparts.

The first hypothesis I set out to test was whether there was a decline in monetary

statistic.

${ }^{10}$ See Fuller (1976, Table 8.5.2. second panel) for 100 observations.

"The Newey-West standard errors allowed for six significant covariances, with a dampening factor of .33 in the corresponding window. 
balances following the introduction of the chervonets. The introduction of the chervonets appears to have decreased the demand for Soviet rubles directly as measured by the negative coefficient on the variable Cher. In addition, the elasticity of money demand -the critical parameter to determine the effects on the bubble- also falls significantly, being equal to -1.79 before the introduction of the indexed currency and -4.05 after the reform. An additional process of decline in money demand took place through progressive financial adaptation as captured by the negative time trend.

The consistent estimates of the semielasticities obtained from (34) allowed me to compute the value of $\phi$. For the pre-chervonets period, $\phi=1.56$; after the introduction of the chervonets, $\phi=1.25$. The bubble term grows slower under the indexed currency system than before. In this sense, I have that the rate of inflation required to sustain the bubble falls as an indexed currency is incorporated.

I next proceeded to test for the relevance of the bubble, by estimating the appropriate inflation prediction equation (33). Following Flood and Garber (1980), I ran the corresponding SW regression for

$$
\pi_{t}=\delta+\beta_{1} \sigma_{t-1} \ldots+\beta_{k} \sigma_{t-k}+A_{0} \phi^{t}+A_{1} \phi^{t^{*}}+v_{t}
$$

which is appropriate as long as an $A R(k)$ model is sufficient to describe the $\sigma$ process. The two bubbles have the time variables normalized for comparison. I tested for a bubble $\left(A_{0}\right)$ between August 1922 and November 1922, ie., prior to the introduction of the chervonets, and for a second bubble $\left(A_{1}\right)$ between January 1923 until the redemption of the Soviet rubles in April 1924. The SW regression ${ }^{12}$ for (35) gave coefficients equal to 0.0068

\footnotetext{
${ }^{12}$ I added to the regression the differences in the rate of money growth for which I could not reject the null of integratedness. In this case I added current and two forward lags and set $k=6$.
} 
for the first bubble and 0.02 for the second. The corresponding t-statistics are 0.58 and 2.90 , respectively. From this, I conclude that there was no bubble prior to the introduction of the chervonets but that one developed shortly thereafter. Computation of the bubble indicates that it was responsible for about 80 percent of the inflation rate toward the end of the hyperinflation. ${ }^{13}$ The $A D F_{3}$ statistic on the residuals of this regression equals -5.54 , clearly rejecting nonstationarity.

My model accounts both for the decline in monetary balances after the introduction of the indexed currency and for the importance of bubbles in accounting for the hyperinflationary process. Unfortunately, a comparison between the two bubbles is not possible for this case because prior to the introduction of the chervonets, there was no bubble; the inflationary process was basically driven by fundamentals. I next analyzed a case in which there were clearly two hyperinflation episodes to allow for a comparison in the bubble terms.

\subsection{The Argentine Hyperinfiations}

Argentina has a long history of inflationary financing. During the 1980 s the rate of inflation increased substantially, reaching hyperinflationary levels during the period May-August of 1989. During the hyperinflation, extensive financial adaptation took place, and the degree of dollarization increased substantially. (See Sturzenegger (1991) and Dornbusch, Sturzenegget and Wolf (1990)). A stabilization program implemented in August 1989 stabilized the economy until December. After mid-December, inflation increased once again and remained high until March.

The two Argentine hyperinflations were the conclusion of decades of excessive reliance

\footnotetext{
${ }^{13} \mathrm{My}$ methodology allowed me test for bubbles for any arbitrary period. If alternative dates are tried for the time span of the bubble, similar results oblain.
} 
on seigniorage to finance government spending. What makes these experiences extremely relevant for the model at hand is the deepening of financial adaptation during the first hyperinflation. The second hyperinflation therefore took place with many more alternative monetary assets already in place and therefore allowed to test the predictions of the model.

At an informal level, one could argue in favor of my model by noticing that inflation reached 200 percent during the first hyperinflation but only 100 percent during the second. In both cases, the reduction in real monetary holding was equivalent. ${ }^{14}$ This suggests that the rate of inflation required to reduce monetary holdings decreased substantially in the short time span between the two hyperinflations.

More formally, I first tested for the integratedness of real money and the inflation rate. ${ }^{15}$ The $A D F_{6}$ statistics for real monetary balances and inflation equal 0.44 and -1.14 , which when compared with the critical value of -2.89 do not allow rejection of the hypothesis of integratedness. ${ }^{16}$ I then estimated the SW money demand equation, obtaining

$$
\begin{aligned}
m_{t}= & 6.45+0.67 D_{t}-0.82 \pi_{t}-0.73\left(\pi_{t} D_{t}\right)-.017 t \\
& (145.33)(9.28) \cdot(-5.34)(-6.10)(-7.64)
\end{aligned}
$$

where $m_{t}$ is real holdings of Argentine australes, $\pi_{t}$ is the inflation rate, and $t$ is a time trend. The dummy $D_{t}$ takes a value of one for periods after July 1989, i.e., after the end of the first hyperinflation. The time trend captures the progressive process of financial

\footnotetext{
${ }^{14}$ The trough in the level of real money holdings attained a value of 4.93 for the first hyperinflation and of 4.90 for the second. This level corresponds to a decline of 18 percent from the previous peak for the first hyperinflation and a fall of 15 percent from the previous peak for the second hyperinflation.

${ }^{15}$ The data was obtained from Indicadores de Coyuntura, FIEL, Bs. As., several issues.

${ }^{10}$ See Fuller (1976, Table 8.5.2. second panel) for 100 observations.
} 
adaptation that takes place in high inflation situations.

Again, for the parameters of the equation to converge to the true population moments, we equation (36) must be a cointegration equation. A standard $A D F_{3}$ test gave a statistic of -2.95 , rejecting the hypothesis of nonstationarity at the 5 percent level. I conclude then that (36) is a cointegrating vector and that the parameters converge to the true population moments.

The first hypothesis I wanted to test was whether there was a decline in monetary balances after the first hyperinflation. Notice that, from (36), the semielasticity of money demand equals -.82 before the introduction of the indexed currency and -1.65 after the reform. Also an additional process of decline in money demand took place through a progressive financial adaptation, as captured by the negative time trend.

The consistent estimates of the semielasticities obtained from (36) allowed me to compute the value of $\phi$. Before the first hyperinflation, $\phi=2.22 ;$ after, $\phi=1.61$. Again, the rate of growth of inflation is much smaller under currency substitution.

I estimated (35) the inflation prediction equation, using the same methodology as I described for the previous example. I allowed for bubbles between March and July 1989 and between November 1989 and March 1990. Both bubbles appear strongly significant with coefficients (t-statistics) of $.026(15.10)$ and $.059(9.16)$ for the first and second hyperinfiation, respectively. From the t-statistics we conclude that bubbles are statistically significant components of an explanation of Argentine hyperinflations. Again, I tested for cointegratedness of this regression using an $A D F_{3}$ test. I got a statistic of -3.62 , which easily rejects the null of nonstationarity.

Table 1 shows the inflation rate and the bubble for the two Argentine hyperinflations. The second bubble is the larger initially but grows more slowly as the rate of inflation 
Table 1: Bubbles in the Argentine llyperinflations

\begin{tabular}{|ccc|ccc|}
\hline \multicolumn{3}{c}{ First Hyper } & \multicolumn{3}{c}{ Second Hyper } \\
\hline Date & Inflation & Bubble & Date & Inflation & Bubble \\
\hline $1989: 3$ & .17 & .06 & $1989: 11$ & .07 & .10 \\
$1989: 4$ & .33 & .12 & $1989: 12$ & .40 & .16 \\
$1989: 5$ & .78 & .29 & $1990: 1$ & .79 & .26 \\
$1989: 6$ & 1.14 & .63 & $1990: 2$ & .62 & .44 \\
$1989: 7$ & 1.97 & 1.41 & $1990: 3$ & .96 & .72 \\
\hline
\end{tabular}

required to induce people to hold less money is reduced by the process of financial adaptation, dollarization, or introduction of currency indexation. The second hyperinflation bubble reaches a smaller value than the corresponding one for the first hyperinflation, this is fully consistent with the predictions of the model.

\section{Conclusions}

This paper studied the implications of introducing an "indexed" or "backed" currency on the monetary equilibrium of an economy with fiat currency. To analyze this question, I constructed a model with a utility function with two currencies. I showed that such utility function will exhibit negative cross-partial between the two monies. Contrary to the conventional wisdom, I found that in that in a rational expectations hyperinflationary solution in which both monetary assets are substitutes, the introduction of a backed currency reduces the rate of depreciation of the original money along the hyperinflation path.

The introduction of the indexed currency induces a process of currency substitution 
across steady states. Upon introduction of the second currency, a price level jump takes place for the original one, reducing its real value. This substitution effect has been stressed in the previous literature. What this paper shows is that it is incorrect to infer from this that the equilibrium rate of inflation of the original currency should increase. On the contrary, by lowering the marginal utility of the existing currency, the indexed currency reduces the inflation rate required to sustain a path with declining real monetary holdings of the original currency. In my model, with fixed money growth, this will result in a smaller rate of growth of inflation.

Additionally if the original currency is experiencing a hyperinflation at the time the new currency is introduced, then the shift to the backed currency occurs gradually. In the long run, the whole system shifts in the long run to the better currency. In this model, we get a Gresham's Law in reverse: good money displaces bad.

The model is then tested empirically for the experiences of Soviet Union during the early 1920s and for Argentina during the late 1980s. The evidence shows an increase in the semielasticity of money demand consistent with the implications of the model. I showed that the bubble grows at a smaller rate when two currencies exist, validating the model's implication that the rate of inflation required to sustain the hyperinflationary equilibrium is smaller under the presence of an alternative currency.

The effects on welfare can be analyzed from the first order conditions for the agent's maximization problem. The utility of the representative agent is maximized at the point at which the marginal utilities of both currencies equal zero, i.e., where $\sigma_{1}=\sigma_{2}=-\delta$ (at the Friedman rule solution). A hyperiuflation equilibrium is extremely costly in terms of welfare because it increases the nominal interest rate, thereby inducing people to save on cash holdings. The introduction of the indexed currency, presumably with a lower 
$\sigma$, improves upon the hyperinflationary equilibrium with one currency by providing an alternate currency that more closely satisfies the Friedman rule. This is not only because it provides a channel by which people can substitute their demand to a currency with a lower "relative price" but also because the rate of inflation of the original currency may actually decrease as well. Contrary to the results of some researchers who have cautioned about the risks of financial adaptation because of its exacerbating inflationary effects (see, for example, De Gregorio (1991) and Dornbusch and Reynoso (1989)), the results of this study wholly support the introduction of an indexed currency.

\section{References}

[1] Bomberger, W. A. and Makinen, G. "Indexation, Inflationary Finance, and Hyperinflation: the 1945-1946 Hungarian Experience." Journal of Political Economy, Vol.88, No.31, 1980 .

[2] Bomberger, W. A. and Makinen, G.; "The Hungarian Hyperinflation and Stabilization of 1945-1946.” Journal of Political Economy, Vol. 91, No.51, 1983.

[3] Cagan, Phillip "The Monetary Dynamics of Hyperinflation" edited by Milton Friedman Studies in the Quantity Theory of Money. Chicago: University of Chicago Press. 1956.

[4] Calvo, Guillermo; "Currency Substitution and the Real Exchange Rate." Journal of International Money and Finance, Vol. 4, 1985, pp. 175-188.

[5] Cassella, Alessandra "Testing for Rational Bubbles with Exogenous or Endogenous Fundamentals." Journal of Monetary Economics, Vol. 24, 1989. 
[6] De Gregorio, Jose "Welfare Costs of Inflation, Seigniorage, and Financial Innovation." IMF Working Paper Number WP/91/1, 1991.

[7] Dornbusch, Rudiger and Reynoso Alejandro "Financial Factors in Economic Develop. ment." American Economic Review, Paper and Proceedings, Vol. 79, No. 2, 1989.

[8] Dornbusch, Rudiger, Sturzenegger, Federico A., and Wolf, Holger "Extreme Infiation: Dynamics and Stabilization." Brookings Papers on Economic Activity, No. 2, 1990, pp 1-84.

[9] Engel, Charles "The Trade Balance and Real Exchange Rate under Currency Substitution." Journal of International Money and Finance, Vol. 8, 1989, pp. 47-58.

[10] Engle Robert and Granger C.W.J. "Cointegration and Error Correction: Representa. tion, Estimation and Testing." Econometrica, Vol. 55, No. 2, 1987, pp. 251-276.

[11] Feenstra, Robert C. "Functional Equivalence between Liquidity Costs and the Utility of Money." Journal of Monetary Economics, Vol. 19, 1986, pp. 271.291.

[12] Flood, Robert P. and Garber, Peter M. "Market Fundamentals Versus Price-level Bubbles: The First Tests." Journal of Political Economy, Vol. 88, No. 4, 1980, pp. 745-769.

[13] Flood Robert P., Garber Peter M. and Scott, L. "Further Tests on Bubbles." Journal of Economic Dynamics and Control, Vol. 8, 1984.

[14] Fuller, W. A. Introduction to Statistical Time Series. New York: John Wiley\&Sons, 1976. 
[15] Kaldor, Nicholas "A study in Inflation, I-Hungary's Classical Example." Manchester Guardian, 21 November 19:16a.

[16] Kaldor, Nicholas; "A study in Inflation, II-Stabilization", Manchester Guardian, 22 November 1946b.

[17] Katzenellenbaum, S. Russian Currency and Banking 1914-1924. London:P.S. King\&Son, LTD. ,1925.

[18] Keller, A. Das Notgeld. Munich: Battenberg Verlag, 1958.

[19] Liviatan, Nissan "Monetary Expansion and Real Exchange Rate Dynamics." Journal of Political Economy, Vol 89, 1981, pp. 1218-1228.

[20] Newey Whitney and West Kenneth; "A Simple, Positive-Definite Heteroskedasticity and Autocorrelation Consistent Covariance Matrix." Econometrica, 1987.

[21] Nogaro B. "Hungary's recent monetary Crisis and its Theoretical Meaning." American Economic Review, Vol. 38, 1948.

[22] Obstfeld, Maurice and Rogof, Kenneth; "Speculative Hyperinflations in Maximizing Models: Can we Rule them Out?." Journal of Political Economy, Vol. 91, 1983.

[23] Sidrauski, Miguel "Rational Choice and Patterns of Growth in a Monetary Economy." American Economic Review, Papers and Proceedings, Vol. 57, 1967.

[24] Stock, James H. "Asymptotic Properties of Least Squares Estimators of Cointegrating Vectors $^{n}$, Econometrica Vol. 55, No. 5, 1987, pp. 1035-1056. 
[25] Stock, James H. and Watson, Mark W. "A Simple MLE of Cointegrating Vectors in Higher-Order Integrated System." NBER Technical Working Paper No 83, December 1989.

[26] Sturzenegger, Federico A. "Financial Adaptation and the Timing of Financial Liber. alization in Eastern Europe." in Finance and the International Economy:5 edited by Richard O'Brien, pp. 94-105, Oxford University Press, 1991.

[27] Yurovsky, L. Currency Problems and Policy of the Soviet Union. London: Leonard Parsons, 1925. 